\title{
Laryngopharyngeal Reflux and Asthma
}

\author{
Łukasz Dembiński*, Aleksandra Banaszkiewicz and Piotr Albrecht
}

Department of Pediatric Gastroenterology and Nutrition, Medical University of Warsaw, Poland

\begin{abstract}
The gastroesophageal reflux presence in asthma has been the subject of many studies indicating their frequent coexisting. The essence of this correlation is not entirely clear and several hypotheses can be found in literature. Recently defined laryngopharyngeal reflux and studies on its impact on the course of asthma seem to bring us closer to understanding this issue. In the last years we gained access to the new diagnostic methods allowing direct registration of laryngopharyngeal reflux. This paper summarizes laryngopharyngeal reflux diagnostic possibilities including the most advanced technologies. It also evaluates published clinical studies, which investigated laryngopharyngeal reflux in asthma patients, both in adults and children.
\end{abstract}

Keywords: Laryngopharyngeal reflux; Asthma; pH-monitoring; Impedance; $\mathrm{Dx}-\mathrm{pH}$

\section{Introduction}

Laryngopharyngeal reflux (LPR) is usually defined as the passage of the gastric contents through the esophagus into the pharynx and/ or larynx that causes troublesome symptoms and/or complications. Although the LPR has been suspected to be one of exacerbating factors for asthma over the past few decades, the real association between these two common diseases has not been established yet. There are many studies that investigated gastroesophageal reflux (GER), which is defined as the retrograde flow of gastric contents into the esophagus, in asthma patients [1-3], but only a few of them were dedicated to the assessment LPR. This article focuses on the findings about clinical studies assessing LPR in patients with asthma in both adults and children.

\section{Etiopathogenesis}

There are many potential mechanisms of mutual influence between asthma and LPR. Predisposition factors of reflux occurring in patients with asthma generally include: weakened the lower esophageal sphincter (LES)-barrier by an increased negative pressure in the thorax, autonomic dysregulation with heightened vagal tone, transient LES relaxations (TLESRs) due to airway obstruction and reduction of LES pressure by asthma medications e.g. $\beta 2$-adrenergic agonists [4-6].

The factors that contribute to the occurrence of asthma or its exacerbations in patients with reflux include: vagal esophago-bronchial reflex, local neuronal reflexes, microaspirations that cause increased bronchial reactivity and bronchoconstriction, direct induction of respiratory epithelium inflammation by the refluxate [7-10]. Although all these factors suggest that LPR may play a substantial role in the clinical manifestation of asthma, the exact relationship between the two diseases remains indefinite.

\section{Diagnostic Methods}

Laryngopharyngeal reflux initial diagnosis is essentially based on the assessment of clinical picture, which appears to be different from gastroesophageal reflux disease (GERD). Usually it does not include complaints from the upper gastrointestinal tract, e.g. heartburn, abdominal pain, nausea, and postprandial bouncing. Predominant symptoms of LPR are mostly limited to ear, nose and throat (ENT), and pulmonological symptoms such as hoarseness, chronic cough, postnasal drip, throat-clearing, sensations of something sticking in the throat or even choking episodes and breathing difficulties. The severity of these complaints can be evaluated using various scales [11]. However, the most widely used and best validated is the Reflux Symptoms Index (RSI) [12]. RSI questionnaire contains 9 symptoms, which are rated by the patient according to the severity of those ailments. Total score above the defined threshold indicates a high probability of the LPR diagnose, but does not guarantee it [13].

The initial assessment of LPR in adults is often based (similarly as in GERD) on the empirical treatment with high doses of proton pump inhibitors (PPI) [14]. However, there is no clear consensus on effectiveness, dosage and length of this treatment [15-17]. Moreover, empirical management seems to be associated with poor compliance in comparison with the treatment preceded by a diagnosis based on pH-monitoring [18].

In order to objectify and refine the diagnosis, endoscopic and functional examination can be used. In ENT specialist practice it is commonly laryngoscopy, which may reveal posterior laryngitis, swelling of the vocal folds (Reinke's edema), vocal cord nodules, mucosal metaplasia ("white-line") or laryngeal pseudo-sulcus and ulceration [19]. These signs are summarized in reflux finding score (RFS) scale [20], but none of them is characteristic only of LPR (RFS sensitivity at most is up to $88 \%$ and specificity up to $38 \%$ ) $[21,22]$. Similarly, esophageal mucosa damage revealed in esophagogastroduodenoscopy may also occur in other conditions (e.g. GERD, eosinophilic esophagitis). Moreover, esophagitis is present in less than $20 \%$ of patients with LPR [23].

Another group of LPR diagnostic methods consists of widely used functional tests, which measure $\mathrm{pH}$ in the upper part of gastrointestinal tract. This allows direct observation of retrograde bolus migration. The main disadvantage of most of these tests is the lack of measurement in laryngopharyngeal region, which seems to be crucial for LPR diagnosis.

*Corresponding author: Łukasz Dembiński, Department of Pediatric Gastroenterology and Nutrition, Medical University of Warsaw, Public Pediatric Teaching Hospital, Działdowska 1, 01-184 Warsaw, Poland, Tel/Fax: +48224523310; E-mail: lukaszdembinski@gmail.com

Received June 30, 2013; Accepted July 23, 2013; Published July 29, 2013

Citation: Dembiński Ł, Banaszkiewicz A, Albrecht P (2013) Laryngopharyngeal Reflux and Asthma. J Aller Ther S11: 008. doi:10.4172/2155-6121.S11-008

Copyright: (c) 2013 Dembiński $Ł$, et al. This is an open-access article distributed under the terms of the Creative Commons Attribution License, which permits unrestricted use, distribution, and reproduction in any medium, provided the original author and source are credited. 
Classical pH-metry ("gold standard" in GERD diagnostic work-up) records the $\mathrm{pH}$ drops only in the distal esophagus. In its dual-probe version, the measurement range is extended to the upper esophageal sphincter (UES), but it does not exceed it. Furthermore, proper placement of proximal sensor is difficult and artifacts of drying of the electrode are present, therefore dual- $\mathrm{pH}$ is not recommended in the guidelines [24,25]. Multichannel intraluminal impedance (MII) also does not allow pharyngeal $\mathrm{pH}$ recording; however, it is very valuable in assessing character and propagation of the refluxate [26]

Only a few new techniques enable determining $\mathrm{pH}$ exactly in the oropharynx. The pharyngeal $\mathrm{pH}$-metry (Dx-pH) has a teardrop shape sensor, which detects aerosolized as well as liquid contents, resists drying and mucus covering [27]. Dx-pH is positioned without a need for X-ray, manometry or endoscopy guidance, but it only measures the $\mathrm{pH}$ in the oropharynx without correlation with GER. This disadvantage does not apply to the hypopharyngeal multichannel intraluminal impedance (HMII), which additionally distinguishes acid and non-acid refluxes [28.] However, HMII has been introduced very recently and requires further testing. Remaining doubts concern the origin of the $\mathrm{pH}$ drops in oropharynx, which do not always correlate with observed episodes of GER [29].

There are possibilities of determining the presence of pepsin and other digestive enzymes in the respiratory tract, saliva or in exhaled breath, but so far they are neither validated nor widely used [30-32].

Despite several attempts, the multitude of diagnostic procedures results in an absence of clearly defined standards of LPR diagnostic. Nonetheless, monitoring $\mathrm{pH}$ above the UES in hypo/oropharynx seems to be the most acknowledged and reliable evaluation method.

\section{Clinical Studies}

The number of studies assessing the association between LPR and asthma is limited and they are very heterogeneous. Lack of standardized definitions for LPR and asthma symptoms, small sample size, absence of control group and variation in age groups limit the value of these studies. However, the main findings of these studies are summarized below.

Eryuksel et al. in their study from 2006 enrolled 28 adults with asthma. The diagnosis of LPR was based on symptoms assessment and videolaryngoscopy [33]. LPR was present in 75\% (21/28) of cases. In these patients PPI treatment (pantoprazole for 3 months) was administered with statistically significant improvement both in the symptoms of asthma and LPR. Despite the small study group and the lack of a control, this paper shows a high prevalence of LPR in asthma and the potential effectiveness of PPI treatment.

In 2007 Wiener et al. published their study on Dx-pH monitoring in detection of LPR in patients with extraesophageal symptoms (2 of them had asthma) [34]. The researchers conducted a simultaneous dual-channel $\mathrm{pH}$-metry and Dx-pH. LPR was present in one patient with asthma $(1 / 2,50 \%)$.

In the Makosiej et al. study of children with chronic inflammation of respiratory system, 3 patients had asthma [35]. Based on Dx-pH evaluation in 2 cases $(66 \%)$ LPR was confirmed. In both of the above pilot studies very small groups of patients were examined, which makes it problematic to draw any conclusions.

Onyekwere's et al. paper from 2010 compared the results of reflux symptoms basing on questionnaires filled in by 98 adults with asthma and 71 controls [36]. Additionally, Dx-pH monitoring in 12 cases (5 with asthma) was performed. There were no statistically significant differences between the two groups, with the prevalence of reflux of $30-35 \%$ (based on symptoms). Moreover, reflux was confirmed by $\mathrm{pH}-$ metry only in $80 \%(4 / 5)$ of asthmatics and in $100 \%$ of controls. As in the previous study, the patient group was very small.

In 2011, Banaszkiewicz et al. conducted a clinical study involving 21 children with difficult-to-treat asthma [37]. LPR was diagnosed in more than $60 \%$ of patients. Positive correlation between the diagnosis of LPR and degree of asthma control $(\mathrm{p}=0.012)$ as well as intensity of treatment was demonstrated. The main limitation of the study was the relatively small group of patients, although it was statistically sufficient.

In 2013, Kilic et al. published their study on correlation of asthma and LPR [38]. 50 children (from 150 diagnosed with asthma) were randomly enrolled and divided in two groups according to the asthma control status-controlled and uncontrolled asthma. Double probe $\mathrm{pH}$ monitoring and laryngoscopy were performed. In $70 \%$ of patients LPR was diagnosed, but there was no statistically significant difference between the two groups $(\mathrm{p}=0.8)$. Additionally, laryngeal findings did not enable the researchers to differentiate between children with and without LPR. As in the previous papers, the study group was relatively small.

Komatsu et al. performed HMII on patients with adult-onset asthma [39]. 70\% of 31 subjects had abnormal proximal pH exposure in upright body position, which was considered, despite the cases of normal values of composite score, an evidence of extra-esophageal reflux. 20 patients underwent antireflux surgery with the outcome of asthma symptoms reduction in $90 \%$ of cases. This study confirmed the high prevalence of reflux in patients with asthma and also seems to prove causality of this relation.

There are numerous studies, performed with dual $\mathrm{pH}$-probes or MII, on coexistence of asthma and GERD, but their review was not a purpose of this paper.

\section{Conclusions}

This article reveals a paucity of clinical data regarding the association between LPR and asthma. There are only a few studies with small or very small samples, without control group and providing varying disease definitions. Moreover, different techniques for LPR detection were used in these studies. All together, they do not allow firm conclusions to be drawn on the role of LPR in asthma. More wellplanned studies are strongly needed to establish it.

\section{References}

1. Harding SM (2005) Gastroesophageal reflux: a potential asthma trigger Immunol Allergy Clin North Am 25: 131-148.

2. Havemann BD, Henderson CA, El-Serag HB (2007) The association between gastro-oesophageal reflux disease and asthma: a systematic review. Gut 56 1654-1664.

3. Tolia V, Vandenplas $Y$ (2009) Systematic review: the extra-oesophageal symptoms of gastro-oesophageal reflux disease in children. Aliment Pharmaco Ther 29: 258-272.

4. Lodi U, Harding SM, Coghlan HC, Guzzo MR, Walker LH (1997) Autonomic regulation in asthmatics with gastroesophageal reflux. Chest 111: 65-70.

5. Zerbib F, Guisset O, Lamouliatte H, Quinton A, Galmiche JP, et al. (2002) Effects of bronchial obstruction on lower esophageal sphincter motility and gastroesophageal reflux in patients with asthma. Am J Respir Crit Care Med 166: 1206-1211

6. Crowell MD, Zayat EN, Lacy BE, Schettler-Duncan A, Liu MC (2001) The effects of an inhaled beta(2)-adrenergic agonist on lower esophageal function: a dose-response study. Chest 120: 1184-1189. 
7. Pearson JP, Parikh S, Orlando RC, Johnston N, Allen J, et al. (2011) Review article: reflux and its consequences - the laryngeal, pulmonary and oesophageal manifestations. Conference held in conjunction with the 9th International Symposium on Human Pepsin (ISHP) Kingston-upon-Hull, UK, 21-23 April 2010. Aliment Pharmacol Ther 33: 1-71.

8. Davis RS, Larsen GL, Grunstein MM (1983) Respiratory response to intraesophageal acid infusion in asthmatic children during sleep. J Allergy Clin Immunol 72: 393-398.

9. Hamamoto J, Kohrogi H, Kawano O, Iwagoe H, Fujii K, et al. (1997) Esophageal stimulation by hydrochloric acid causes neurogenic inflammation in the airways in guinea pigs. J Appl Physiol 82: 738-745.

10. Jack Cl, Calverley PM, Donnelly RJ, Tran J, Russell G, et al. (1995) Simultaneous tracheal and oesophageal $\mathrm{pH}$ measurements in asthmatic patients with gastro-oesophageal reflux. Thorax 50: 201-204.

11. Andersson $O$ (2009) Laryngopharyngeal reflux-development and refinement of diagnostic tools. Intellecta DocuSys AB. V. Frölunda, Sweden.

12. Belafsky PC, Postma GN, Koufman JA (2002) Validity and reliability of the reflux symptom index (RSI). J Voice 16: 274-277.

13. Friedman M, Hamilton C, Samuelson CG, Kelley K, Taylor R, et al. (2012) The value of routine $\mathrm{pH}$ monitoring in the diagnosis and treatment of laryngopharyngeal reflux. Otolaryngol Head Neck Surg 146: 952-958.

14. Masaany M, Marina MB, Sharifa Ezat WP, Sani A (2011) Empirical treatment with pantoprazole as a diagnostic tool for symptomatic adult laryngopharyngeal reflux. J Laryngol Otol 125: 502-508.

15. Karkos PD, Wilson JA (2006) Empiric treatment of laryngopharyngeal reflux with proton pump inhibitors: a systematic review. Laryngoscope 116: 144-148.

16. Shin MH, Nam SY, Park YH, Son YI (2012) Open-Label Observational Study for Evaluating the Short-term Benefits of Rabeprazole Medication on Laryngopharyngeal Reflux. Clin Exp Otorhinolaryngol 5: 28-33.

17. Reichel O, Dressel H, Wiederänders K, Issing WJ (2008) Double-blind placebo-controlled trial with esomeprazole for symptoms and signs associated with laryngopharyngeal reflux. Otolaryngol Head Neck Surg 139: 414-420.

18. Friedman M, Maley A, Kelley K, Pulver T, Foster M, et al. (2011) Impact of pH monitoring on laryngopharyngeal reflux treatment: improved compliance and symptom resolution. Otolaryngol Head Neck Surg 144: 558-562.

19. Neri G, Pugliese M, Castriotta A, Mastronardi V, Pasqualini P, et al. (2013) White-line: a new finding in laryngopharyngeal reflux objective evaluation. Med Hypotheses 80: 769-772.

20. Belafsky PC, Postma GN, Koufman JA (2001) The validity and reliability of the reflux finding score (RFS). Laryngoscope 111: 1313-1317.

21. Powell J, Cocks HC (2013) Mucosal changes in laryngopharyngeal refluxprevalence, sensitivity, specificity and assessment. Laryngoscope 123: 985991.

22. Watson NA, Kwame I, Oakeshott P, Reid F, Rubin JS (2013) Comparing the diagnosis of laryngopharyngeal reflux between the reflux symptom index, clinical consultation and reflux finding score in a group of patients presenting to an ENT clinic with an interest in voice disorders. A pilot study in thirty-five patients. Clin Otolaryngol. [Epub ahead of print].

23. Vaezi MF (2004) Laryngitis and gastroesophageal reflux disease: increasing prevalence or poor diagnostic tests? Am J Gastroenterol 99: 786-788

24. McCollough M, Jabbar A, Cacchione R, Allen JW, Harrell S, et al. (2004) Proximal sensor data from routine dual-sensor esophageal $\mathrm{pH}$ monitoring is often inaccurate. Dig Dis Sci 49: 1607-1611.

25. Hirano I, Richter JE; Practice Parameters Committee of the American College of Gastroenterology (2007) ACG practice guidelines: esophageal reflux testing Am J Gastroenterol 102: 668-685.

26. Ford CN (2005) Evaluation and management of laryngopharyngeal reflux. JAMA 294: 1534-1540.

27. Ayazi S, Lipham JC, Hagen JA, Tang AL, Zehetner J, et al. (2009) A new technique for measurement of pharyngeal $\mathrm{pH}$ : normal values and discriminating $\mathrm{pH}$ threshold. J Gastrointest Surg 13: 1422-1429.

28. Hoppo T, Sanz AF, Nason KS, Carroll TL, Rosen C, et al. (2012) How much pharyngeal exposure is "normal"? Normative data for laryngopharyngeal reflux events using hypopharyngeal multichannel intraluminal impedance (HMII). J Gastrointest Surg 16: 16-24.

29. Becker V, Graf S, Schlag C, Schuster T, Feussner H, et al. (2012) First agreement analysis and day-to-day comparison of pharyngeal $\mathrm{pH}$ monitoring with $\mathrm{pH} /$ impedance monitoring in patients with suspected laryngopharyngeal reflux. J Gastrointest Surg 16: 1096-1101.

30. Knight J, Lively MO, Johnston N, Dettmar PW, Koufman JA (2005) Sensitive pepsin immunoassay for detection of laryngopharyngeal reflux. Laryngoscope 115: $1473-1478$

31. Printza A, Speletas M, Triaridis S, Wilson J (2007) Is pepsin detected in the saliva of patients who experience pharyngeal reflux? Hippokratia 11: 145-149.

32. Davies-Husband CR, Zaman S, Whinney DJ (2012) Testing for laryngopharyngeal reflux in exhaled breath condensate: a pilot study. Clin Otolaryngol 37: 497-498

33. Eryuksel E, Dogan M, Golabi P, Sehitoglu MA, Celikel T (2006) Treatment of laryngopharyngeal reflux improves asthma symptoms in asthmatics. J Asthma 43: $539-542$.

34. Wiener GJ, Tsukashima R, Kelly C, Wolf E, Schmeltzer M, et al. (2009) Oropharyngeal $\mathrm{pH}$ monitoring for the detection of liquid and aerosolized supraesophageal gastric reflux. J Voice 23: 498-504

35. Makosiej R, Durko A, Trzeciak-Jedrzejczyk A, Malecka M, Kosielska J, et al. (2010) Pharyngo-laryngeal $\mathrm{pH}$-metry in the diagnostics of chronic inflammation of respiratory system-a pilot study. Gastroenterol Pol 17: 339-342.

36. Onyekwere CA, Adeyeye OO, Ogbera AO, Duro-Emmanuel F (2010) Prevalence of gastroesophageal reflux disease among patients with bronchial asthma. Trop Gastroenterol 31: 195-198.

37. Banaszkiewicz A, Dembinski L, Zawadzka-Krajewska A, Dziekiewicz M, Albrecht P, et al. (2013) Evaluation of laryngopharyngeal reflux in pediatric patients with asthma using a new technique of pharyngeal $\mathrm{pH}$-monitoring. Adv Exp Med Biol 755: 89-95

38. Kilic M, Ozturk F, Kirmemis O, Atmaca S, Guner SN, et al. (2013) Impact of laryngopharyngeal and gastroesophageal reflux on asthma control in children. Int J Pediatr Otorhinolaryngol 77: 341-345.

39. Komatsu Y, Hoppo T, Jobe BA (2013) Proximal reflux as a cause of adultonset asthma: the case for hypopharyngeal impedance testing to improve the sensitivity of diagnosis. JAMA Surg 148: 50-58.

This article was originally published in a special issue, Asthma handled by Editor. Dr. Manar A Nader, Mansoura University, Egypt 